\title{
The effectiveness of
}

\section{clonidine as an analgesic in paediatric adenoton- sillectomy}

Eleanor J. Reimer MD FRCPC,

Gillian S. Dunn MBBS DCH FRCA, Carolyne J. Montgomery MD FRCPC,

Peter M. Sanderson MBCHB FRCA, Louis D. Scheepers BSC MBBCH FRCPC, Pamela M. Merrick BSN

Purpose: To compare the analgesic effects of preoperative oral clonidine with intraoperative intravenous fentanyl in children undergoing tonsillectomy or adenotonsillectomy.

Methods: This randomized, controlled, double-blind study of 36 ASA I-II children, age 7-12 yr undergoing adenotonsillectomy was conducted at a tertiary care paediatric teaching hospital. Either $4 \mu \mathrm{g} \cdot \mathrm{kg}^{-1}$ clonidine po was given 60-90 min preoperatively or $3 \mu \mathrm{g}^{\mathrm{kg}}-1$ fentanyl iv was given intraoperatively. Postoperatively visual analog pain scores (VAS) were recorded at rest and on swallowing every $10 \mathrm{~min}$ for the first $30 \mathrm{~min}$ and then every 15 min for two hours. Morphine $0.05 \mathrm{mg} \cdot \mathrm{kg}^{-1}$ iv was given for VAS $\geq 5$. If $>3$ doses were required, $1.5 \mathrm{mg} \cdot \mathrm{kg}^{-1}$ codeine po and $20 \mathrm{mg} \cdot \mathrm{kg}^{-1}$ acetaminophen po were given. Sedation and anxiety scores were recorded preoperatively. Haemodynamic changes, blood loss, recovery scores, and the incidence of vomiting, hypotension, and airway obstruction were recorded.

Results: Children who received clonidine had a higher incidence of preoperative sedation (63\%) than those receiving fentanyl (6\%). Preinduction mean arterial pressure was lower in the clonidine group but required no intervention. VAS scores were similar throughout the observation period. There was no difference either in the number of morphine or codeine rescue doses administered or in the incidence of side effects.

Conclusion: Oral clonidine is an effective analgesic and sedative for children undergoing tonsillectomy or adenotonsillectomy.

Objectif : Comparer les effets analgésiques de l'administration orale de clonidine préopératoire et de fentanyl intraveineux peropératoire chez des enfants devant subir une amygdalectomie ou une adéno-amygdalectomie.

Méthode : Cette étude randomisée, contrôlée et à double insu a porté sur 36 enfants ASA I-II, âgés de 7 à 12 ans, devant subir une adéno-amygdalectomie dans un hôpital universitaire de soins pédiatriques tertiaires. On a administré $4 \mathrm{ug} \cdot \mathrm{kg}^{-1}$ de clonidine po $60-90$ min avant l'intervention ou $3 \mathrm{ug} \cdot \mathrm{kg}^{-1}$ de fentanyl iv au cours de l'intervention. Les niveaux de douleur ont été enregistrés après l'opération, à l'aide de l'échelle visuelle analogue (EVA), au repos et lors de la déglutition à toutes les 10 min pendant les 30 premières min et à toutes les 15 min pen-

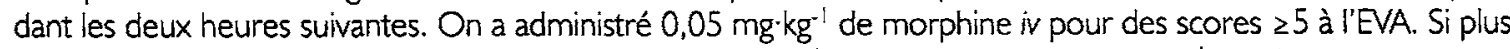
de 3 doses étaient nécessaires, on a donné aussi $1,5 \mathrm{mg} \cdot \mathrm{kg}^{-1}$ de codéine po et $20 \mathrm{mg} \cdot \mathrm{kg}^{-1}$ d'acétaminophène po. Avant l'intervention, on a enregistré les niveaux de sédation et d'anxiété. Les changements hémodynamiques, les pertes sanguines, les niveaux de récupération et l'incidence de vomissements, d'hypotension et d'obstruction du conduit aérien ont été notés.

Résultats : Les enfants qui ont reçu de la clonidine ont présenté une plus grande incidence de sédation préopératoire $(63 \%)$ que ceux qui ont reçu du fentanyl (6\%). Avant l'induction de l'anesthésie, la tension artérielle moyenne était plus basse dans le groupe qui avait reçu de la clonidine, mais cela n'a pas nécessité de traitement. Les valeurs de l'EVA ont été similaires tout au long de la période d'observation. II n'y avait pas de différence non plus quant au nombre de doses de rattrapage de morphine ou de codéine administrées ou quant à l'incidence d'effets secondaires.

Conclusion : La clonidine par voie orale est un analgésique et un sédatif efficace chez des enfants qui subissent une amygdalectomie ou une adéno-amygdalectomie.

From the Department of Anaesthesia, University of British Columbia and British Columbia's Children's Hospital, 4480 Oak Street, Room 1L.2, Vancouver, B.C. V6H 3V4, Canada.

Address correspondence to: Dr. E.J. Reimer, Phone: 604-875-2711; Fax: 604-875-3221; E-mail: elreimer@interchange.ubc.ca This study was funded by a grant from the Vancouver Foundation and presented in part at the Annual General Mceting of the Canadian Anaesthetists' Society, June 1997.

Accepted for publication September 12, 1998 


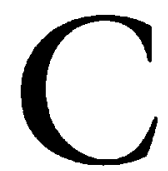

LONIDINE is an analgesic that acts centrally at the locus coeruleus in the brain stem and locally at the spinal cord. ${ }^{1}$ As a non-opioid analgesic, clonidine provides analgesia without opioid side-effects, most importantly respiratory depression. It has several additional effects including sedation, decreased salivation, decreased anaesthetic requirement, improved perioperative haemodynamic stability, and decreased vomiting. ${ }^{2,3}$ It has varying bioavailability as an oral, transdermal, and parenteral preparation and has been administered by the epidural, intravenous, oral and rectal routes in children. . $^{4}$

Published paediatric experience with oral clonidine is limited. Oral administration of clonidine as premedication to provide sedation for children undergoing ophthalmological surgery has been studied. ${ }^{5}$ A preoperative dose of $4 \mu \mathrm{g} \cdot \mathrm{kg}^{-1}$ provided good to excellent sedation, superior to diazepam, allowing separation from parents and acceptance of the face mask for anaesthetic induction. In this study oral atropine 0.03 $\mathrm{mg} \cdot \mathrm{kg}^{-1}$ was included in the premedication and no difficulties were encountered with hypotension or bradycardia. Oral clonidine has also been investigated as an analgesic in children undergoing minor surgery. A dose of $4 \mu \mathrm{g} \cdot \mathrm{kg}^{-1}$ was found to reduce objective pain scores and analgesic requirements for $12 \mathrm{hr}$ postoperatively. ${ }^{8}$

Adenotonsillectomy may result in considerable intraoperative blood loss that can be exacerbated by inadequate anaesthetic depth. ${ }^{9}$ In addition, extreme agitation during recovery can potentially disrupt the freshly coagulated tonsillar bed, and increase the risk of postoperative bleeding. Children presenting for adenotonsillectomy may also have airway obstruction due to hypertrophied tissue. This may be associated with obstructive sleep apnea syndrome. These children are at even greater risk of airway obstruction postoperatively due to oropharyngeal oedema and the concomitant use of opioid analgesics. ${ }^{10}$

An anaesthetic technique that would ensure preoperative sedation, haemodynamic stability, and postoperative analgesia would be very beneficial. A decrease in the use of opioid analgesics and their concomitant side effects such as nausea, vomiting, and respiratory depression, may improve outcome in adenotonsillectomy patients.

The purpose of this study was to examine the use of preoperative oral clonidine as an analgesic for children undergoing either tonsillectomy or adenotonsillectomy.

\section{Methods}

A prospective, randomized blinded study was conducted at British Columbia's Children's Hospital, a tertiary care paediatric institution. Thirty-six, ASA class I-II children between the ages of 7-12 yr presenting for elective adenotonsillectomy were recruited for the study. Exclusion criteria included inability to understand English, contraindications to any of the medications used in the study, obesity (> 90th percentile on weight nomograms), inability to use a visual analogue scale, and the use of any preoperative sedative hypnotic or analgesic medications.

After obtaining institutional review board approval and informed, written parental and patient consent where appropriate, the children were randomly assigned to one of two groups by pharmacy using a random numbers table. Group 1 received $4 \mu \mathrm{gg} \cdot \mathrm{kg}^{-1}$ clonidine po to a maximum of $200 \mu \mathrm{g}, 60-90 \mathrm{~min}$ preoperatively. Group 2 received oral placebo 60 - 90 min preoperatively. The clonidine was prepared in pharmacy by crushing commercially available tablets and placing the powder into clear gelatin capsules in fixed dose intervals according to weight. Both groups received EMLA cream in preparation for intravenous induction. All children were instructed on the use of a $10 \mathrm{~cm}$ Visual Analogue Scale (VAS) and were questioned as to what pain experience had previously scored 10/10. Immediately before coming to the OR, the subjects were assessed by a blinded Day Care Unit (DCU) nurse for the presence or absence of dizziness. In addition, the degree of sedation and anxiety on separation from their parents were graded using a four point scale. (Table I)

In the operating room, monitors were applied and preinduction heart rate (HR) and blood pressure were recorded using a non-invasive automated blood pressure measuring device. Intravenous access was established and anaesthesia was induced with $5 \mathrm{mg} \cdot \mathrm{kg}^{-1}$ propofol mixed with $0.5 \mathrm{mg} \cdot \mathrm{kg}^{-1}$ lidocaine iv. Tracheal intubation was facilitated with $0.2 \mathrm{mg} \cdot \mathrm{kg}^{-1}$ mivacurium iv. Patients in Group 1, the clonidine group, then received intravenous placebo and those in group 2 received $3 \mu \mathrm{g} \cdot \mathrm{kg}^{-1}$ fentanyl iv. Anaesthesia was maintained with nitrous oxide, oxygen, and isoflurane. Prior to surgical incision, the surgeon infiltrated the tonsillar fossae with bupivacaine $0.25 \%$ with 1:200,000 epinephrine to a maximum of $2.5 \mathrm{ml}$ per side. Heart rate and mean arterial pressure (MAP) changes $>20 \%$ were recorded. The time of administration of the study drugs, induction drugs, local anaesthetic, time of the end of surgery, end of anaesthetic, extubation time, and the amount of blood loss including the volume collected via suction and on sponges were recorded. Postoperatively, the children were extubated after return of protective airway reflexes and transferred to the postanaesthetic care unit (PACU). 
TABLE I

\begin{tabular}{ll}
\hline & Sedation Scale \\
\hline 1 & Alert/agitated \\
2 & Awake \\
3 & Drowsy \\
4 & Asleep \\
& Anxiety Scale \\
\hline 1 & Combative \\
2 & Tearful \\
3 & Apprehensive \\
4 & Calm \\
& Recovery Scale \\
\hline 1 & Unarousable \\
2 & Sleeping but rousable \\
3 & Awake, calm \\
4 & Awake, restless \\
5 & Awake, agitated \\
\hline
\end{tabular}

TABLE II Demographic Data for Clonidine and Fentanyl Groups

\begin{tabular}{lll}
\hline & $\begin{array}{l}\text { Clonidine } \\
n=19\end{array}$ & $\begin{array}{l}\text { Fentanyl } \\
n=17\end{array}$ \\
\hline Age $(\mathrm{yr}){ }^{*}$ & $8(7-12)$ & $8(7-11)$ \\
$W_{\text {eight }(\mathrm{kg}){ }^{*}}$ & $30(20-45)$ & $29(24-48)$ \\
Gender $(\mathrm{M} / \mathrm{F}) \dagger$ & $11 / 8$ & $8 / 9$ \\
Tonsillectomy/Adenotonsillectomy $\dagger$ & $10 / 9$ & $8 / 9$ \\
Duration of Procedure (minutes) * & $15(6-43)$ & $16(12-52)$ \\
\hline
\end{tabular}

* median (range)

$\dagger$ count

TABLE III Side Effects of Anaesthesia and Surgery in Clonidine and Fentanyl Groups

\begin{tabular}{llll}
\hline & Clonidine & Fentanyl & $P$ \\
\hline Anxiety score $<4 \dagger$ & $6(32 \%)$ & $4(25 \%)$ & .72 \\
Sedation score $>2 \dagger$ & $12(63 \%)$ & $1(6 \%)$ & .0004 \\
Preinduction HR (BPM) $\ddagger$ & $84 \pm 14$ & $89 \pm 12$ & .32 \\
Preinduction MAP $(\mathrm{mm} \mathrm{Hg})$ & $68(54-103)$ & $80(61-97)$ & .046 \\
HR/MAP changes $>20 \% \dagger$ & $11(58 \%)$ & $6(35 \%)$ & .18 \\
Blood loss $(\mathrm{mL}) *$ & $10(0-140)$ & $20(1-110)$ & .28 \\
\hline
\end{tabular}

* median (range)

$\dagger$ count (\%)

$\ddagger$ mean \pm SD

On arrival in the PACU, self report pain scores were assessed using a $10 \mathrm{~cm}$ VAS. Pain scores were determined both at rest and on swallowing every 10 $\mathrm{min}$ for the first $30 \mathrm{~min}$ and then every $15 \mathrm{~min}$ for a total of two hours by an independent blinded observer. Morphine $0.05 \mathrm{mg} \cdot \mathrm{kg}^{-1} i \mathrm{p}$ was given for rest pain scores 25 . If either VAS scores remained $\geq 5$ or $>$ three
TABLE IV Morphine Doses in PACU in Clonidine and Fentanyl Groups

\begin{tabular}{|c|c|c|c|}
\hline & Clonidine & Fentanyl & $P$ \\
\hline $\begin{array}{l}\text { Patients receiving morphine } \dagger \\
\text { Morphine } \mathrm{mg} \cdot \mathrm{kg}^{-1} \text { * } \\
\text { \# of doses per patient }\end{array}$ & $\begin{array}{l}12(63 \%) \\
0.05(0-.21) \\
1(0-4) \\
\end{array}$ & $\begin{array}{l}12(71 \%) \\
0.10(0-.15) \\
2(0-3)\end{array}$ & $\begin{array}{l}.65 \\
.57 \\
.66 \\
\end{array}$ \\
\hline \multicolumn{4}{|l|}{$\begin{array}{l}* \text { median (range) } \\
\dagger \text { count }(\%)\end{array}$} \\
\hline \multicolumn{4}{|c|}{$\begin{array}{l}\text { TABLE V Patients receiving Codeine/Acetaminophen Doses in } \\
\text { DCU }\end{array}$} \\
\hline & Clonidine & Fentanyl & $P$ \\
\hline $\begin{array}{l}\text { Codeine } \dagger \\
\text { Acetaminophen } \dagger\end{array}$ & $\begin{array}{l}6(33 \%) \\
7(39 \%)\end{array}$ & $\begin{array}{l}4(24 \%) \\
5(29 \%)\end{array}$ & $\begin{array}{l}.71 \\
.55\end{array}$ \\
\hline
\end{tabular}

$\dagger$ count (\%)

TABLE VI 24 hour Postoperative Interview

\begin{tabular}{llll}
\hline & Clonidine & Fentanyl & $P$ \\
\hline 24 hr vomiting $\dagger$ & $3(17 \%)$ & $5(29 \%)$ & .44 \\
After discharge analgesics $\dagger$ & $16(89 \%)$ & $14(82 \%)$ & .66 \\
Satisfaction score * & $9(8-10)$ & $8(2-10)$ & .35 \\
Excessive sedation $\dagger$ & $3(17 \%)$ & $2(12 \%)$ & 1.0 \\
\hline
\end{tabular}

* median (range)

† count (\%)

doses of morphine were required, $1.5 \mathrm{mg} \cdot \mathrm{kg}^{-1}$ codeine $p o$ and $20 \mathrm{mg} \cdot \mathrm{kg}^{-1}$ acetaminophen $p o$ were then given.

Recovery scores (Table I) were assessed at the same time intervals as pain scores. During the postoperative period, the incidence of vomiting, the need for airway support for obstruction, and the incidence of hypotension or blood loss requiring ip volume replacement were also recorded.

After transfer to the Day Care Unit (DCU), if the child had pain scores 25 at rest and oral analgesia had not previously been given, $1.5 \mathrm{mg} \cdot \mathrm{kg}^{-1}$ codeine $p o$ and $20 \mathrm{mg} \cdot \mathrm{kg}^{-1}$ acetaminophen po were administered. In children who were discharged the same day, a sedation score was measured at time of discharge.

A telephone interview was conducted at $24 \mathrm{hr}$ after discharge to inquire about excessive sedation (yes/no), vomiting (yes/no), the use of analgesics, and overall satisfaction rating (scale of $1-10$, with 1 being very dissatisfied with the overall experience, to 10 being very satisfied).

\section{Statistical Analysis}

The initial assumption for sample size calculations was that those children who received intraoperative fen- 
tanyl would require two doses of morphine (50 $\left.\mathrm{mg} \cdot \mathrm{kg}^{-1}\right)(\mathrm{SD} \pm 1)$ in the PACU and that the use of clonidine would reduce the requirement to one dose $(S D \pm 1)$. For the study to have a power of 0.8 , a sample size of 18 subjects per group would be required, given an alpha of 0.05 .

All numerical data were tested for normality using the Martinez-Iglewicz, the Kolmorgorov-Smirnov, and the D'Agostino-Pearson Omnibus K2 tests. Data that were normally distributed were summarized with mean \pm SD. Skewed data were summarized with median (range). The variables measured over time were skewed (VAS pain), ordinal (recovery, anxiety, sedation scales), or categorical (vomiting, airway support, iv resuscitation), or lacked compound symmetry and therefore could not be analyzed by repeated measures ANOVA. Categorical data measured over time were summarized. Normally distributed data were analyzed for between group differences using unpaired $t$ tests. Skewed data were analyzed using Mann-Whitney tests. Some ordinal data had to be condensed to categorical due to small frequencies. Categorical data were analyzed by chisquare or Fisher exact tests as appropriate. Bonferroni's correction was applied for repeated comparisons where appropriate. A $P$ value of $<0.05$ was considered significant except where Bonferroni's correction was applied.

\section{Results}

Forty-one children were enrolled in the study but only 36 were included in the final analysis. Three were removed due to breach of protocol. In addition, one child had attention deficit disorder and was unable to cooperate with VAS scoring postoperatively and another child had a prolonged stay in the PACU due to post extubation croup requiring racemic epinephrine.

The median age of the subjects in both groups was $8 \mathrm{yr}$ (range 7-12).(Table II) The groups were also similar in weight, distribution of gender and procedure performed (tonsillectomy and adenotonsillectomy). Median time of administration of clonidine to induction was 65 min (range 46-95). Duration of the procedure, time to extubation, and recovery scores were similar. (Table II)

Children in the clonidine group had a higher incidence of preoperative sedation with $12(63 \%)$ coming to the OR drowsy or asleep compared with one $(6 \%)$ child in the fentanyl group $(P=0.004)$. There was no difference in anxiety scores. (Table III)

Preinduction heart rate was first measured on arrival in the operating room. The preinduction heart rate was $84 \pm 14$ BPM in the clonidine group which was not different from that in the fentanyl group, 89 $\pm 12 \mathrm{BPM}$. No subject required atropine to treat clin-

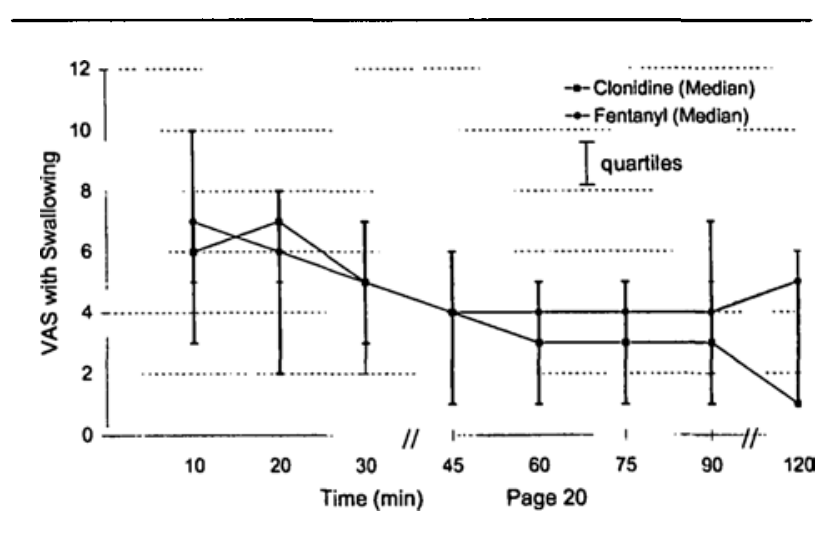

FIGURE VAS Pain Scores

ically important bradycardia. Preinduction median arterial pressure (MAP) in the clonidine group was lower with a median of $68 \mathrm{mmHg}(54-103)$ than in the fentanyl group with a median of $80 \mathrm{mmHg}$ (6197) $(P=.046)$. Eleven children in the clonidine group had HR or MAP changes $>20 \%$ compared with six in the fentanyl group. None required active intervention to treat these changes. There was no difference in blood loss between the two groups. (Table III)

The VAS scores were similar in the two groups at all points during the two hour observation period except at time 0 .(Figure 1 ) At time 0 , only three children in the clonidine group $v s$ eight children in the fentanyl group were awake. Therefore, the numbers were too few to accurately summarize graphically. There was no difference in morphine requirement between the two groups. (Table IV) There was also no difference in the requirement for codeine and acetaminophen in the DCU. (Table V) One child in each group received acetaminophen without codeine.

In the outpatient subjects, there was no difference in time to discharge between the two groups. Outpatient discharge criteria for tonsillectomy patients require a minimum six hour stay. At the time of discharge three (18\%) children in the clonidine group were sedated compared with none in the fentanyl group. The degree of sedation did not delay discharge.

Data from parental assessment of the incidence of vomiting, analgesic requirements, sedation, and general satisfaction during the first $24 \mathrm{hr}$ postoperatively were not different between the groups. (Table VI)

\section{Discussion}

This study demonstrated the efficacy of clonidine as an analgesic for adenotonsillectomy but did not show that the use of clonidine was superior to fentanyl in 
the immediate postoperative period. We chose to compare clonidine with fentanyl because we felt that the control group should receive an intraoperative analgesic in addition to local anaesthetic. We limited our observation period to the first two hours postoperatively as this is the time when most doses of $i v$ opioids are administered to ensure analgesia and when complications such as airway obstruction become apparent. If we had continued our observation period for $24 \mathrm{hr}$, the prolonged action of clonidine may have demonstrated ongoing analgesic effects possibly superior to fentanyl. A greater difference in analgesia may also have been more apparent if the study design had excluded local anaesthetic infiltration.

No children in either group had respiratory complications postoperatively. A larger study would be needed to demonstrate the beneficial effect of clonidine on minimizing complications associated with opioid use.

Mikawa's study demonstrated the analgesic effect of clonidine by studying 90 children undergoing a variety of surgical procedures. ${ }^{8}$ Most (73\%) of the procedures were strabismus correction but minor urologica and otological procedures were also studied. The control group in this study received no intraoperative analgesic which is ethical for procedures that do not cause significant postoperative pain. A wider age range of children was studied necessitating the use of an objective pain scale (OPS) rather than a self-report measure such as a visual analogue scale. However, the OPS may not be able to differentiate between the sedative and the analgesic effects of medication. ${ }^{11}$

We chose to limit this study to children undergoing tonsillectomy or adenotonsillectomy because these procedures result in moderate to severe postoperative pain. We also studied an age group that was able to cooperate with a self-report visual analogue pain scale to minimize the difficulties associated with interpretation of objective pain scores. The separation of affective issues from nociceptive intensity can complicate the assessment of pain in younger children.

A prolonged analgesic effect of clonidine might have been demonstrated by more rigorous methodology in the assessment of after discharge pain and analgesic usage. Parents have been shown to "under-medicate" children postoperatively. ${ }^{12}$ A prolonged analgesic effect may be advantageous compared to the shorter acting analgesic effects of intravenous opioids only available to patients while in hospital.

This study demonstrates the efficacy of clonidine as a preoperative sedative. A potential drawback to its use in the DCU setting is the prolonged onset of action of the oral preparation. The use of the intravenous preparation would solve this problem in that it could be administered at the time of induction of anaesthesia or by infusion postoperatively. No adverse effects were noted by sending these children home after six hours observation. The use of oral clonidine for children to be discharged after a shorter stay may be inappropriate because of the potential effect of excessive sedation. This deserves further study.

Clonidine has haemodynamic side effects. Although no children in our study required treatment for bradycardia or hypotension, younger children may require anticholinergic premedication to prevent important bradycardia and decreased cardiac output. ${ }^{13}$ The safety of clonidine in this younger age group has not been established.

In conclusion, oral clonidine is a readily available, effective analgesic and sedative for children undergoing tonsillectomy or adenotonsillectomy. Its use allows a reduction in the use of opioid analgesics. Further studies are needed to determine the safety of clonidine in a younger population, in children with obstructive sleep apnea, and in different pain models.

\section{Acknowledgments}

The authors wish to thank the Department of Otolaryngology at British Columbia's Children's Hospital for allowing us to study their patients, the nursing staff of the Day Care Unit and the Postanaesthetic Care Unit, and Dr. Clayton Reichert, Department of Anaesthesia, for their assistance in conducting the study.

\section{References}

1 Tong C, Eisenach JC. 2 Adrenergic agonists. In: New Drugs in Anesthesia: Part II. Anesthesiology Clinics of North America. Philadelphia: W.B. Saunders, 1994; 12: 49-63.

2 Maze $M$, Tranquillii $W$. Alpha-2 adrenoceptor agonists: defining the role in clinical anesthesia. Anesthesiology 1991; 74: 581-605.

3 Mikawa $K$, Nisbina $K$, Maekawa $N$, Asano $M$, Obara $H$. Oral clonidine premedication reduces vomiting in children after strabismus surgery. Can J Anaesth 1995; 42: 977-81.

4 Jamali S, Monin S, Begon C, Dubousset A-M, Ecoffey C. Clonidine in pediatric caudal anesthesia. Anesth Analg 1994; 78: 663-6.

5 Mikawa K, Maekawa N, Nishina K, Takao $\Upsilon$, Taku $H$, Obara $H$. Efficacy of oral clonidine premedication in children. Anesthesiology 1993; 79: 926-31.

6 Bernard J-M, Hommeril J-L, Passuti N, Pinaud $M$. Postoperative analgesia by intravenous clonidine. Anesthesiology 1991; 75: 577-82. 
7 Lönnqvist PA, Bergendabl HTG, Eksborg S.

Pharmacokinetics of clonidine after rectal administration in children. Anesthesiology 1994; 81: 1097-101.

8 Mikawa K, Nishina K, Maekawa N, Obara $H$. Oral clonidine premedication reduces postoperative pain in children. Anesth Analg 1996; 82: 225-30.

9 Kendrick D, Gibbin K. An audit of the complications of paediatric tonsillectomy, adenoidectomy and adenotonsillectomy. Clin Otolaryngol 1993; 18: 115-7.

10 Rosen GM, Muckle RP, Mabowald MW, Goding GS, Ullevig $C$. Postoperative respiratory compromise in children with obstructive sleep apnea syndrome: can it be anticipated? Pediatrics 1994; 93: 784-8.

11 Broadman LM, Rice LJ, Hannallah RS. Oral clonidine and postoperative pain (Letter). Anesth Analg 1997; 84: 229.

12 Finley GA, McGrath PJ, Forward SP, McNeill G, Fitzgerald $P$. Parents' management of children's pain following 'minor' surgery. Pain 1996; 64: 83-7.

13 Nishina K, Mikawa K, Maekawa N, Obara H. Oral clonidine premedication blunts the heart rate response to intravenous atropine in awake children. Anesthesiology 1995; 82: 1126-30. 